NBER WORKING PAPER SERIES

\title{
DO PROPERLY ANTICIPATED PRICES FLUCTUATE RANDOMLY? EVIDENCE FROM VIX FUTURES MARKETS
}

\author{
George O. Aragon \\ Rajnish Mehra \\ Sunil Wahal \\ Working Paper 24575 \\ http://www.nber.org/papers/w24575 \\ NATIONAL BUREAU OF ECONOMIC RESEARCH \\ 1050 Massachusetts Avenue \\ Cambridge, MA 02138 \\ May 2018, Revised December 2018
}

We thank Hank Bessembinder and seminar participants at Arizona State University for useful comments and the Center for Investment Engineering at Arizona State University for support. George O. Aragon had a paid consulting relationship with the Securities and Exchange Commission that ended April 2018. Sunil Wahal is a consultant to Dimensional Fund Advisors. DFA provided no funding or data for this research. The views expressed herein are those of the authors and do not necessarily reflect the views of the National Bureau of Economic Research.

NBER working papers are circulated for discussion and comment purposes. They have not been peer-reviewed or been subject to the review by the NBER Board of Directors that accompanies official NBER publications.

(C) 2018 by George O. Aragon, Rajnish Mehra, and Sunil Wahal. All rights reserved. Short sections of text, not to exceed two paragraphs, may be quoted without explicit permission provided that full credit, including $(\odot$ notice, is given to the source. 
Do Properly Anticipated Prices Fluctuate Randomly? Evidence from VIX Futures Markets George O. Aragon, Rajnish Mehra, and Sunil Wahal

NBER Working Paper No. 24575

May 2018, Revised December 2018

JEL No. G1,G12,G13,G14

\section{ABSTRACT}

The VIX index is not traded on the spot market. Hence, in contrast to other futures markets, the VIX futures contract and spot index are not linked by a no-arbitrage condition. We examine (a) whether predictability in the VIX index carries over to the futures market, and (b) whether there is independent time series predictability in VIX futures prices. The answer to both questions is no. Samuelson (1965) was right: VIX futures prices properly anticipate predictability in volatility, and are themselves unpredictable.

George O. Aragon

Arizona State University

George.Aragon@asu.edu

Rajnish Mehra

Department of Economics

W. P. Carey School of Business

Arizona State University

PO Box 879801

Tempe, AZ 85287-9801

and NBER

rajnish.mehra@asu.edu
Sunil Wahal

Arizona State University

Sunil.Wahal@asu.edu 


\section{Introduction}

Do properly anticipated prices fluctuate randomly? Samuelson (1965) famously posed this rhetorical question, writing down, in his words, a "sweeping" theorem in which prices follow a martingale. Fama's $(1965,1970)$ route to a similar conclusion is statistical and culminates in the epigram "prices fully reflect all available information". ${ }^{1}$ The question is ultimately an empirical one, as Samuelson eloquently points out: "Deductive analysis cannot determine whether the empirical properties of the stochastic model I posit come at all close to resembling the empirical determinants of today's realworld markets". Despite decades of attention, however, academic consensus on this issue remains elusive.

Samuelson (1965) wrote his theorem in the context of futures prices where the underlying spot market was a commodity (wheat), and the straw man was "normal backwardation" as in Keynes (1930), Houthakker (1961), and Cootner (1960). Commodity futures have a natural tether in the prices of the underlying spot market, which when properly adjusted by a cost of carry, build in an arbitrage mechanism. In this paper, we re-address Samuelson's rhetorical question to a specific market: VIX futures contracts. There are three reasons why this market is uniquely informative. First, the underlying spot market is expected volatility and is not independently

\footnotetext{
${ }^{1}$ Subsequent work by LeRoy (1973), Lucas (1978), and Prescott and Mehra (1980), shows that in an 'informationally efficient' market with risk averse agents, it is marginal utility weighted prices that follow a martingale.
} 
traded. $^{2}$ Consequently, the arbitrage mechanism from the spot market is absent, offering an uncommonly interesting test of the martingale property. Second, volatility is stationary, persistent in the short-run and mean-reverting over longer horizons (see, for example, Grünbichler and Longstaff (1996), and Mencia and Sentana (2013)). Thus, Samuelson's question is à propos in the sense that predictability in the underlying spot market can, but need not, imply predictability in the futures market. ${ }^{3}$ Third, the VIX futures market (along with the market for VIX options and Exchange Traded Notes (ETNs)) is extensively used by investors to hedge volatility. Mixon and Onur (2014) document that the VIX futures market is twice the size of the variance swap market at the short end of the maturity spectrum. Moreover, a number of investment managers and consultants recommend VIX futures-based investment strategies. ${ }^{4} \quad$ Understanding predictability in this market is therefore important from an asset pricing perspective, as well as for investors trading in this instrument. In a risk neutral world, Samuelson's

\footnotetext{
${ }^{2}$ A trader cannot synthesize the VIX index for a variety of reasons, including but not limited to, the fact that the portfolio of underlying options necessary to synthesize future levels of the VIX are different from those available today. Full details of the VIX construction process, the difficulties of replication, and the inclusion of SPX Weekly options, is reported by the CBOE (https://www.cboe.com/micro/vix/vixwhite.pdf).

${ }^{3}$ Samuelson (1965) motivates his martingale theorem for futures with the idea that predictability in underlying commodities can, but need not, lead to predictability in futures prices: "Is it an exception that spot wheat prices generally rise (presumably because of storage costs) from the July harvest time to the following spring and drop during June...But surely spot prices ought to vary with shifts in such supply and demand factors as weather, crop yields, cross plantings; or population, income and taste changes. Who says that weather must itself display no serial correlation?" He goes on to illustrate the theorem with four different stochastic processes for the underlying commodity.

${ }^{4}$ The market for investment advice in trading volatility is large, as evidenced by an internet search of VIX-based trading strategies. Two prominent examples are McFarren (2013), and Winig, Tongberg, and Jones (2011).
} 
(1965) theorem implies that the spot market should not be able to predict changes in futures prices.

In stark contrast to the above, Moskowitz et al. (2012) document significant time series momentum in commodity, bond, and equity index futures. The persistence in returns that they document exists for every single futures contract in their sample, all of which are explicitly linked by a no arbitrage condition to the underlying asset. In this paper, we also examine whether their conclusions carry over to a setting where there is no such arbitrage condition.

Our empirical investigation covers the complete history of the VIX futures contract from its inception in 2004 to 2017. Our tests pose two questions: (a) can the current VIX index level predict future price changes in the futures contract, and (b) do prior returns in VIX futures predict future price changes. The former relies on predictability in volatility, based either on persistence in the short-run, or mean reversion in the long-run. The latter is the time series momentum strategy studied by Moskowitz et al. (2012).

To examine Samuelson's hypothesis, we estimate time series regressions of returns on futures contracts between $t$ and $t+1$, on the level of the VIX at $t-1$. We also use demeaned levels of the VIX, thus allowing for variation from the long-run mean. Since the horizon over which mean reversion occurs is uncertain, we demean using an extended trailing mean from the start of the VIX, as well as an average calculated over 
the prior 36 months. We estimate regression coefficients using daily, weekly and monthly returns. At all horizons, the slopes on the level and demeaned-level of the VIX at t-1 are statistically indistinguishable from zero. In addition, trading strategies that go long or short the futures contract when the VIX falls below or rises above one standard deviation from the estimated means do not generate excess returns. This nonresult has a powerful implication: predictability in the underlying mean-reverting series does not generate predictability in the futures price. ${ }^{5}$

To assess momentum in VIX futures, we estimate time series regressions of current period returns on lagged returns, while controlling for VIX levels. At daily, weekly and monthly horizons, the slopes on lagged returns are statistically indistinguishable from zero. We also build time series momentum trading strategies that exploit overlapping portfolios using a variety of lookback and holding periods. The returns to such strategies, unadjusted for risk or transaction costs, are suggestive of momentum in VIX futures, particularly for lookback periods under six months. For instance, with a lookback and holding period of three months, the average return to a dynamic time series momentum strategy is 2.18 percent per month.

\footnotetext{
${ }^{5}$ One could also ask whether the futures term structure predicts VIX futures returns. Koijen et al. (2018) use Carry, defined as the return to the futures position when the spot price stays constant, to predict futures returns. Bessembinder (2018) employs an inverse measure, the Roll Yield, defined as the difference between the futures return and the change in the spot price. In the Appendix we show that, as expected, Carry does contain some predictive power for futures returns, consistent with a time varying risk premium. Modeling the term structure or time varying risk premium is beyond the scope of our paper (see Chen (2018), Eraker and Wu (2017), Mencia and Santana (2013)). Our tests pose a more elemental question - whether predictability in the underlying translates into predictability in the futures. To the extent that our regressions fail to reject the null, an appeal to time varying risk premia, or more sophisticated models, is unwarranted.
} 
This gross return does not adjust for the volatility risk premium arising from investors' desire to hedge fluctuations in stock market volatility. Bollen, O'Neill, and Whaley (2017) argue that VIX futures have become the "go-to market for hedging volatility risk" ${ }^{6}$ Cheng (2018) shows that a close cousin of the volatility risk premium, the VIX premium, reliably predicts ex post returns to VIX futures. Mencia and Sentana (2013) document large negative expected returns to VIX futures, as high as 30 percent annually (see also Szado (2009) and Alexander and Korovilas (2013)). On the theoretical front, Eraker and $\mathrm{Wu}$ (2017) show that a dynamic equilibrium model of VIX futures can generate a large volatility risk premium. In light of this literature, it is natural to ask whether the unadjusted returns to the time series momentum strategy described above (2.18 percent per month) are driven by the volatility risk premium. Our evidence indicates that this is indeed the case. The time series momentum strategy is short between 66 and 76 percent of the time and its returns are largely driven by the negative expected return of VIX futures. ${ }^{7}$ Even a naïve adjustment for the volatility

\footnotetext{
${ }^{6}$ For estimates and explanations of the volatility risk premium, see Coval and Shumway (2001), Bakshi and Kapadia (2003), Bollerslev, Tauchen, and Zhou (2009), Carr and Wu (2008), Egloff, Leippold, and Wu (2010), Todorov (2009), Bekaert and Hoerova (2014), Ait-Sahalia, Karaman, and Mancini (2015), and, Dew-Becker, Giglio, Le, and Rodriguez (2017).

${ }^{7}$ Drechsler, Moreira and Savov (2018) find that liquidity provision has a negative exposure to volatility risk and therefore earns the premium. This is indirect (negative) exposure; one could also ask who seeks, and who provides, direct exposure in this marketplace. In unreported results, we examine time series variation in the net long positions of various categories of large traders as reported by the CFTC. Prior to the Financial Crisis, dealers are net short VIX futures, thereby supplying volatility insurance. In the six-month period between December 2008 and June 2009, the CFTC does not report positions. This is because, by rule, at least 20 traders must report positions to the CFTC for aggregate positions to be disclosed (so that individual positions cannot be reverse-engineered). This data gap implies a shutdown of this market precisely when the VIX spiked. After June 2009, traders categorized as "leveraged funds" by the CFTC are net short VIX futures, supplying volatility insurance. Detailed results are available upon request.
} 
risk premium, effected by subtracting the historical average return to VIX futures, eliminates the apparent profitability of the time series momentum strategy. For example, the average monthly return to the 3 month lookback and holding period strategy drops from 2.18 percent to -0.39 percent per month. Adjusting for realistic transaction costs by buying at the prevailing ask and selling at the prevailing bid further reduces the average returns to the strategy; the average return to the 3 month strategy drops to -0.88 percent per month.

In addition to using U.S. data, we consider the VSTOXX index of Eurozone securities and its futures contract. There is no overlap in the stocks included in the VSTOXX and VIX indices but as volatility tends to be correlated across markets, this constitutes a quasi out-of-sample test. As with the VIX, we observe no predictability in VSTOXX futures arising from predictability in the VSTOXX index. Time series momentum strategies that appear to be profitable using unadjusted returns become statistically indistinguishable from zero after appropriate adjustments for risk and transaction costs.

Our results speak to the nature of anticipatory equilibrium in financial markets and the rationality of expectations first described by Muth (1961). Samuelson (1965) was right, at least with respect to VIX futures: properly anticipated prices fluctuate randomly. 
The remainder of the paper proceeds as follows. Section 2 describes the data and provides summary statistics. Section 3 contains predictability and time series momentum tests. Section 4 concludes.

\section{Data sources and summary statistics}

\subsection{Institutional details}

The CBOE Volatility Index (VIX) is the annualized 30-day expected volatility of the S\&P 500 Index calculated from near and next-term call and put option prices with more than 23 days and less than 37 days to expiration (CBOE, 2014). The portfolio of options rolls forward in time and linear interpolation maintains a constant 30 day horizon. Formally, the index is an approximation of the square root of the risk-neutral expectation of the integrated variance (Carr and $\mathrm{Wu}, 2006$ ). The VSTOXX Index is similarly constructed as the 30-day implied volatility index of the Euro STOXX 50 Index, a stock index of 50 blue-chip Eurozone stocks. There is no overlap of the securities included in the VSTOXX index and the S\&P 500.

Standardized futures contracts on the VIX started trading on the CBOE in March 2004. Since 2007, VIX futures is a near 24-hour trading market featuring regular with regular trading hours of 8:30 a.m. - 3:15 p.m. CST, Monday-Friday, and extended trading hours from 3:30 p.m. - 8:15 a.m. CST Monday-Friday. The VSTOXX minifutures introduced by Eurex in 2009, have a similar but not identical trading schedule. 


\subsection{Data and return distributions}

We use Bloomberg to obtain data on VIX and VSTOXX index levels and futures prices at the end of each trading session and the close of the trading day. Our price series is based on the closest-to-maturity contract, rolling to the next contract on t-2 days before expiration. We construct a daily series of returns using successive prices on a contract for delivery on a specific date, and never across contracts with different delivery dates. Returns computed in this manner capture a strategy that closes the position in the near contract two days before expiration and opens a position in the second-nearest contract.

For net positions of various categories of traders in VIX futures, we use the weekly Commitments of Traders (COT) report produced by the CFTC. The CFTC categories traders into four groups: dealer/intermediary, asset manager/institutional, leveraged funds, and others. The gap in traders' commitments between December 2008 and June 2009 reported in footnote 5 is confirmed by the CFTC in private correspondence.

Panel A of Table 1 tabulates descriptive statistics for the VIX index. At a daily frequency, the long-run average level of the VIX index over this period was 18.57 with a standard deviation of 9.07 . It reached a maximum of 80.86 , at the height of the financial crisis and displayed considerable skewness (2.60). The first order autocorrelation of the index is high (0.98). 
Since our subsequent analysis uses a variety of horizons, we report daily, weekly and monthly returns. Weekly returns are constructed from Wednesday-to-Wednesday, and monthly returns are based on calendar months. The majority of the literature uses arithmetic returns (Bessembinder (1992), de Roon, Nijman and Veld (2000), Moskowitz et al. (2012)). We report both arithmetic $\left(\mathrm{R}_{\mathrm{VIX}}\right)$ and continuously compounded returns $\left(\ln \left(1+\mathrm{R}_{\mathrm{VIX}}\right)\right)$ because of the considerable skewness and variance in arithmetic returns. Relative to other financial time series, average arithmetic returns are high: 0.24 percent per day and 1.96 percent per month. Since the standard deviation and skewness are also large, it is not surprising that the continuously compounded returns significantly diverge from arithmetic returns (-0.02 percent per day and -0.17 percent per month). First order autocorrelations are negative, about -0.10 for the daily series and -0.23 in the monthly data, indicative of mean reversion in the VIX. Figure 1 plots the daily level of the VIX together with its historical mean and one standard deviation confidence bands, illustrating the time series variation in the index.

The average daily and monthly arithmetic returns on the futures contract $\left(\mathrm{R}_{\mathrm{F}(\mathrm{VIX})}\right)$ are -0.23 percent and -4.90 percent respectively. In comparison, Eraker and Wu (2017) report an average arithmetic daily return of -0.12 percent from January 2006 to May 2013. This difference stems from the fact that we use the closest-to-maturity contract in computing returns, similar to Moskowitz et al. (2012), while Eraker and Wu (2017) use a weighted average of the front-month and next-month futures contracts. The larger negative returns of near maturity VIX futures is consistent with the 
empirical evidence that volatility premiums are largest on the short-end of the term structure (see, Table 1 in Eraker and $\mathrm{Wu}$ (2017) and Table 2 in Dew-Becker et al. (2017)). At the daily horizon, there is almost no autocorrelation in returns to the futures contract. At the monthly horizon, however, arithmetic returns have a first order autocorrelation of 0.16 , suggestive of some time series momentum.

Panel B contains Spearman correlations between these return series and the CRSP value-weighted index. The correlation between the equity market and the VIX is -0.67 , and between the equity market and the VIX futures is -0.77 . This negative correlation is frequently cited as providing diversification benefits for investors (see, for example, Whaley (2013, Exhibit 4)), a point emphasized by investment managers recommending volatility insurance investment strategies.

Liquidity issues are especially important in the construction of dynamic trading strategies that seek to exploit time series predictability. The average bid-ask spread over the sample period is 0.43 percent but varies considerably over time, reaching well over 1.5 percent at the height of the financial crisis. Average daily volume over this period is 38,000 contracts, corresponding to average dollar volume of over $\$ 38$ million. Note that this is a time series average of only the nearest maturity contract; the average daily volume across all contracts is $\$ 85$ million. Trading volume in VIX futures rises substantially over our sample period, averaging over $\$ 210$ million after 2013 for all contracts. 


\section{Predictability in spot and futures prices}

In this section, we present the results from analyses that seek to understand if predictability in the VIX index generates predictability in futures prices, and if there is independent time series predictability in futures prices.

\subsection{Does predictability in the VIX index imply predictability in the VIX futures?}

There is considerable evidence that volatility is persistent in the short-run but mean-reverting in the long-run. ${ }^{8}$ Our first test to assess whether predictability in the VIX index generates predictability in futures prices employs a univariate regression of VIX futures returns on the prior level of the VIX. We use three variants of the independent variable: (i) the level of the VIX at t-1, (ii) the level of the VIX at t-1 minus a long-run trailing (expanding window) mean calculated from daily observations of the VIX from 1990 through t-1 $\left(\overline{V I X}_{e, t-1}\right)$, and (iii) the level of the VIX at t-1 minus a trailing (rolling window) mean, calculated from the prior 36 months of daily observations $\left(\overline{V I X}_{r, t-1}\right)$. Using the long-run trailing mean (ii), takes the perspective that the VIX is mean-reverting back to a historical average. Specification (iii), using a rolling mean, accounts for local time variation in expected volatility. All specifications are measurable with respect to information at time $t$ and avoid any look-ahead bias. To ensure that our results are robust with respect to time horizons, we estimate regressions using daily, weekly and monthly returns.

\footnotetext{
${ }^{8}$ For example, French et al. (1987), Harvey and Whaley (1992), Sheikh (1993), and Grünbichler and Longstaff (1996) present empirical evidence that index volatility follows a mean-reverting process.
} 
The regressions in the first three columns of Table 2 use arithmetic returns and the last three employ continuously compounded returns. Panels A, B and C are regressions at daily, weekly and monthly horizons respectively. At the daily horizon, the prior level of the VIX has no predictive power for futures returns regardless of whether arithmetic or continuously compounded returns are used. Demeaning using either a long-run or rolling average does not change the results. The intercepts correspond approximately to the average returns in Table 1 because the prior level of the VIX has no explanatory power; the adjusted $\mathrm{R}^{2} \mathrm{~s}$ of the regressions are miniscule.

Results at weekly and monthly horizons follow the same pattern. Predictability in futures prices generated by persistence (mean-reversion) in the VIX implies positive (negative) coefficients on the VIX. The slopes on the prior levels of the VIX have tstatistics that are well below 2.00. Adjusted $\mathrm{R}^{2}$ s rise somewhat with longer horizon but remain small, explaining less than 1 percent of the variation in returns.

Although we work with the entire history of the VIX futures contract, statistical power may pose an issue when using weekly or monthly returns. To address this, we generate a time series of weekly and monthly returns rolling forward each day. We then use these overlapping returns to estimate regressions similar to those in Table 2. Although the slopes of these regressions are unbiased, the standard errors are biased downward. We adjust the standard errors using the Newey and West (1987) methodology with lags equal to the number of days in the overlap. These regressions 
(available upon request), generate inferences very similar to those drawn from the results in Table 2. Some readers may also be interested in whether the term structure of VIX futures (i.e. the "Carry" of Koijen et al. (2018), or the "Roll Yield" of Bessembinder (2018)) influences our inferences. They do not. Full details of regressions that control for the term structure are provided in the Appendix.

We also implement a trading strategy in which an investor enters a long or short position in VIX futures if the current level of the VIX is one standard deviation below or above its historical mean. When the VIX is within one standard deviation of the mean, the strategy stays in cash. The holding period in the futures contract is set to 22 trading days, implying monthly rebalancing. As a result, the shift from cash to long or short positions need not take place at calendar month-end. Figure 2 illustrates this strategy for each trading day in 2007. The upper bars (labelled +1 ) indicate when the strategy is long VIX futures, the lower bars (labelled -1) indicate short positions, and middle bars (labelled 0) indicate periods when the strategy is in cash. The strategy was generally long futures during the earlier part of 2007 when the VIX was relatively low. In contrast, short positions were more common during the latter part of the year when the VIX rose above its mean. Figure 2 also highlights differences between expanding or rolling lookback windows used to compute the mean and standard deviation. The former generates larger standard deviations, resulting in the strategy being in cash more frequently during the high volatility period in the latter part of 2007. 
Table 3 shows average daily returns for four variations of the above strategy. The strategies in Panels A and B are as described above, the former using an expanding window, and the latter using rolling windows. In Panels $\mathrm{C}$ and $\mathrm{D}$, long (short) positions in the futures contract are triggered when the VIX index crosses the one standard deviation boundary and if the prior month's return in the futures contract is positive (negative). The purpose of this "momentum filter" overlay, in the spirit of Moskowitz et al. (2012), is to potentially enhance the strategy by exploiting the monthly autocorrelation in VIX futures returns documented in Table 1.

The first set of columns show unadjusted returns using daily closing prices. The unadjusted returns to the strategies in Panels $\mathrm{A}$ and $\mathrm{B}$ are -0.06 and -0.08 percent per day and statistically indistinguishable from zero. In contrast, the long legs of these strategies have large negative returns, -0.29 and -0.21 percent per day with t-statistics of 2.61 and 2.02 respectively, consistent with the volatility risk premium embedded in VIX futures. To account for this, we also compute volatility risk premium adjusted returns by subtracting the historical average return to VIX futures from 2004 to t- 1 for the long leg of the strategy, and adding it for the short leg. ${ }^{9}$ The average volatility risk premium adjusted returns for these strategies are 0.01 percent per month in both Panels A and B, with t-statistics of 0.19 and 0.08 respectively. This simple volatility risk premium adjustment makes a substantial difference to the long leg of these strategies; using

\footnotetext{
${ }^{9}$ Subtracting the historical average return is a first approximation, much in the spirit of Brown and Warner (1985). In addition to its simplicity, it also has the advantage that it coincides with our approach to adjusting the current level of the VIX with its historical mean.
} 
expanding (rolling) windows, the average daily return to the long leg is only 0.06 percent (0.12 percent). Both are statistically indistinguishable from zero.

The last set of columns account for transactions costs required for implementation. We calculate net returns by appropriately buying at the prevailing ask and selling at the prevailing bid in each rebalance, and then adjusting for the volatility risk premium. Our adjustments are not identical to subtracting average bid-ask spreads or computing midpoint returns for two reasons. First, time series variation in bid-ask spreads could be systematically related to the VIX, rising precisely when the strategy needs to trade (for examples in equity markets, see Nagel (2012) and Conrad et al. (2015)). Second, changes in bid or ask prices need not be symmetric. Ask prices may rise precisely when the strategy needs to buy and bid prices may fall when the strategy needs to sell.

Incorporating these transaction costs further reduces the returns of these strategies. For instance, in Panel A, the volatility risk premium adjusted net returns for the long leg is only 0.01 percent per day (down from 0.06 percent per day using volatility risk premium adjusted returns), with a t-statistic of 0.07 . Finally, Panels $\mathrm{C}$ and $\mathrm{D}$ show the same set of returns for these strategies enhanced by the momentum filter. Unsurprisingly, the filter substantially increases the fraction of the time series in which the strategy remains in cash. Across the board, the unadjusted returns, the 
volatility risk premium adjusted returns, and the transaction cost adjusted returns are small and statistically indistinguishable from zero.

\subsection{Momentum: Regression-based evidence}

To examine time series momentum, we follow Moskowitz et al. (2012) and regress excess arithmetic returns on lagged excess returns as well as lagged levels of the VIX as follows:

$$
R_{F(V I X), t}=\alpha+\beta_{h} R_{F(V I X), t-h}+\delta V I X_{t-1}+\varepsilon_{t}
$$

where the regressions are estimated using daily, weekly, and monthly data using lags of $\mathrm{h}=1,2 \ldots 60$. The regressions generate 60 slopes on lagged returns for each horizon. We summarize them by plotting the t-statistics on these slopes in the three panels in Figure 3 , corresponding to daily, weekly and monthly returns.

At the daily and weekly horizon, the t-statistics on both lagged returns and VIX levels are well below 2.00 at virtually every horizon. Our results at the monthly horizon are notably different from those in Moskowitz et al. (2012). In their regressions, returns are scaled by ex ante volatilities so that instruments with different volatilities are comparable. Pooling all instruments, they report positive t-statistics for the prior 12 months, seven of which are larger than $2.00 .{ }^{10}$ In contrast, the bottom panel of Figure 3

\footnotetext{
${ }^{10}$ In Figure 1A of their paper, the coefficients on prior month returns at lags 1, 2, 3, 10, 11, 12 have tstatistics over 2.00 .
} 
shows no t-statistics above 2.00 in the prior 12 months. Only three of the 12 t-statistics in the prior year are positive and the distribution across lags appears to be random.

\subsection{Momentum: Trading Strategies}

In addition to the above regressions, we consider time series momentum strategies using the portfolio approach of Jegadeesh and Titman (1993). For a variety of lookback and holding periods, we create portfolios that go long (short) the futures contract for the holding period if the return over the lookback period is positive (negative). We use 1, 3, 6, 9, and 12 month lookback and holding periods. Since portfolios are created every month, holding periods for various portfolios overlap in calendar months. The return on calendar month $t$ is the equal-weighted average return across all portfolios with a holding period in that month.

Panel A of Table 4 shows average monthly returns for these strategies. When the lookback period is one month, average monthly returns vary from 3.33 percent for a one-month holding period, to 1.33 percent for a 12 month holding period. Three out of five of the t-statistics for the holding periods are above 2.00, and the remaining are about 1.9. For lookback periods of one, three and six months, and a holding period of one month, average monthly returns are also large. For instance, for the three and six month lookback horizons, the one month holding period returns are 4.43 and 3.13

percent per month respectively. Overall, average returns across all lookback and holding periods are positive and large. 
An important consideration in time series momentum strategies is the degree to which the returns are driven by the long versus the short leg of the strategy. The first column of Table 4 shows the percentage of portfolios for which the momentum strategy is short VIX futures, computed as the time series average of the proportion of all momentum portfolios that are short futures for each lookback period and month. We see that this strategy is short futures 66 percent to 77 percent of the months. This is unsurprising, given that VIX futures earn negative returns on average, and negative returns trigger short positions. The fact that the strategy is often short suggests that the returns to momentum are influenced by the volatility risk premium. As in Table 3, we adjust the returns to the strategy by subtracting the average return to VIX futures from 2004 to t- 1 from the long leg of the strategy, and adding it to the short leg. Panel B reports the average volatility risk premium adjusted returns. Using these adjusted returns, the profitability of the strategy shrinks substantially for all lookback and holding periods. For example, the 1-month lookback and holding period return of 3.33 percent (t-statistic $=1.92)$ in Panel A shrinks to 1.52 percent $(\mathrm{t}$-statistic $=0.88)$ in Panel B. Across the range of lookback and holding periods, average returns are negative in 21 out of 25 combinations.

In Panel $\mathrm{C}$, we adjust the returns to the trading strategy in Panel $\mathrm{B}$ to include real time transaction costs. We implement this by ensuring that each long position is established by buying at the prevailing ask price and selling at the prevailing bid (and vice versa for short positions). If the futures contract needs to be rolled over during the 
holding period, the roll transactions are similarly conducted at the bid and ask. Trading costs further reduce the returns in Panel B. Focusing again on the 1-month lookback and holding period, the average monthly return drops from 1.52 percent in Panel B to 0.36 percent (t-statistic $=0.20$ ) in Panel C. Of the 25 combinations of lookback and holding periods, only two have positive returns, both of which are statistically insignificant.

Our results suggest that a realistic evaluation of time series momentum strategies should incorporate adjustments for risk and transaction costs; very likely, it is these adjustments that account for the difference between our results and those reported in Moskowitz et al. (2012). ${ }^{11}$

\subsection{An "out-of-sample" test: VSTOXX futures}

Figure 4 plots the levels of the VSTOXX index and the VIX index between 1999 and 2017. As expected, the correlation between the two indices is high. We construct return series for the VSTOXX index and its futures contracts in a manner analogous to the VIX. By and large, the statistical properties of the arithmetic and continuously compounded returns on the VSTOXX index and its futures contract are similar to the VIX. Average daily arithmetic (continuously compounded) returns to the futures are 0.19 (-0.27) percent; average monthly arithmetic (continuously compounded) returns are

\footnotetext{
${ }^{11} \mathrm{Kim}$, Tse and Wald (2016) find that the large returns to the time series momentum strategies in Moskowitz et al. (2012) are driven by the volatility scaling of returns. They report that without the scaling, the returns to the time series momentum strategies in these contracts are similar to those of a buy-and-hold strategy.
} 
-3.91 (-5.79) percent. The distributions are generally less skewed than the VIX but the autocorrelations are similar.

Table 5 contains time series regressions for the VSTOXX futures analogous to those reported in Table 2. As before, the table shows regressions for arithmetic and continuously compounded returns at daily (Panel A), weekly (Panel B), and monthly (Panel C) horizons. The results for VSTOXX futures largely mirror those for VIX futures. At the daily and weekly horizon, intercepts pick up the mean returns on the futures contract. The prior level of the VSTOXX index or its demeaned version has no explanatory power for returns on the futures contracts. At the monthly horizon, the slopes on the prior levels of the VSTOXX index are negative but statistically insignificant. Further, the adjusted- $\mathrm{R}^{2}$ s are close to zero in every instance.

Table 6 replicates the returns to time series momentum strategies on VSTOXX futures analogous to VIX futures in Table 4. Panel A shows the unadjusted monthly returns to these trading strategies. There are significant differences between the returns to momentum strategies on VSTOXX futures versus VIX futures. For lookback periods of one and three months, there are positive returns for holding periods up to 12 months. With a six month lookback period, returns are especially high for the first month, and remain high up to six months after portfolio formation. Both returns and their statistical significance decline with longer lookback and holding periods. 
As with VIX futures, adjusting the returns to the VSTOXX momentum strategy with an estimate of the volatility risk premium makes a substantial difference. Panel B shows that the adjusted returns are lower at every lookback and holding period and are statistically indistinguishable from zero in all 25 strategies. Panel $\mathrm{C}$ shows the returns after adjusting for transactions cost in a manner similar to that for VIX futures. The magnitude of the returns declines further, without any change in statistical (in) significance.

\section{Closing remarks}

Samuelson (1965) hypothesized that in an informationally efficient futures markets, futures price changes should be unpredictable. We reconsider his theorem in the VIX futures market where the underlying index may be predictable but is not traded. We look at multiple futures-based trading strategies aimed at exploiting predictability in the VIX index, but find no evidence of predictability in returns on VIX futures contracts. Further, active strategies designed to exploit time series momentum in futures prices do not outperform a buy-and-hold strategy when adjusted for the volatility risk premium and transaction costs. We also conduct an out-of-sample analysis using the VSTOXX index of Eurozone stocks; the conclusions based on our analysis of VIX futures do not change. Our findings strongly support the view that VIX futures prices are unpredictable. 
Current research trends in financial economics have highlighted statistical 'anomalies'. This is due, in part, to the tendency of researchers to publish papers with results that reject the null hypothesis of market efficiency. Our paper serves as a cautionary tale that often, but not always, these eagerly received conclusions are premature, and tend to wilt in the glare of rigorous empirical analysis. 


\section{REFERENCES}

Ait-Sahalia, Y., Karaman, M. and Mancini, L., 2015. The term structure of variance swaps and risk premia. Unpublished Working Paper. Available at SSRN: https://ssrn.com/abstract $=2136820$ or http://dx.doi.org/10.2139/ssrn.2136820.

Alexander, C. and Korovilas, D., 2013. Volatility exchange-traded notes: Curse or cure? The Journal of Alternative Investments, 16(2), p.52.

Bakshi, G. and Kapadia, N., 2003. Delta-hedged gains and the negative market volatility risk premium. The Review of Financial Studies, 16(2), pp.527-566.

Bekaert, G. and Hoerova, M., 2014. The VIX, the variance premium and stock market volatility. Journal of Econometrics, 183(2), pp.181-192.

Bessembinder, H., 1992. Systematic risk, hedging pressure, and risk premiums in futures markets. The Review of Financial Studies, 5(4), pp.637-667.

Bessembinder, H., 2018. The "Roll Yield" myth. Financial Analysts Journal 74, 41-53.

Bollen, N.P., O'Neill, M.J. and Whaley, R.E., 2017. Tail wags dog: Intraday price discovery in VIX markets. Journal of Futures Markets, 37(5), pp.431-451.

Bollerslev, T., Tauchen, G. and Zhou, H., 2009. Expected stock returns and variance risk premia. The Review of Financial Studies, 22(11), pp.4463-4492.

Brown, S.J. and Warner, J.B., 1985. Using daily stock returns: The case of event studies. The Journal of Financial Economics 14, pp 3-31.

Carr, P. and Wu, L., 2006. A Tale of Two Indices. The Journal of Derivatives, 13(3), pp.13-29.

Carr, P. and Wu, L., 2008. Variance risk premiums. The Review of Financial Studies, 22(3), pp.1311-1341.

Cheng, I.H., 2018. The VIX premium. Review of Financial Studies, forthcoming.

Conrad, J., Wahal, S. and Xiang, J., 2015, High frequency quoting, trading and the efficiency of prices, Journal of Financial Economics 116, 271-291. 
Cootner, P.H., 1960. Returns to speculators: Telser versus Keynes. Journal of Political Economy, 68(4), pp.396-404.

Coval, J.D. and Shumway, T., 2001. Expected option returns. The Journal of Finance, 56(3), pp.983-1009.

De Roon, F.A., Nijman, T.E. and Veld, C., 2000. Hedging pressure effects in futures markets. The Journal of Finance, 55(3), pp.1437-1456.

Dew-Becker, I., Giglio, S., Le, A. and Rodriguez, M., 2017. The price of variance risk. Journal of Financial Economics, 123(2), pp.225-250.

Drechsler, I., Moreira, A., and Savov, A., 2018, Liquidity creation as volatility risk, working paper, NYU.

Egloff, D., Leippold, M. and Wu, L., 2010. The term structure of variance swap rates and optimal variance swap investments. Journal of Financial and Quantitative Analysis, 45(5), pp.1279-1310.

Eraker, B. and Wu, Y., 2017. Explaining the negative returns to volatility claims: An equilibrium approach. Journal of Financial Economics, 125(1), pp.72-98.

Fama, E.F., 1965. The behavior of stock-market prices. The Journal of Business, 38(1), pp.34-105.

Fama, E.F., 1970. Efficient capital markets: A review of theory and empirical work. The Journal of Finance, 25(2), pp.383-417.

French, K.R., Schwert, G.W. and Stambaugh, R.F., 1987. Expected stock returns and volatility. Journal of Financial Economics, 19(1), pp.3-29.

Grünbichler, A. and Longstaff, F.A., 1996. Valuing futures and options on volatility. Journal of Banking \& Finance, 20(6), pp.985-1001.

Harvey, C.R. and Whaley, R.E., 1992. Market volatility prediction and the efficiency of the S \& P 100 index option market. Journal of Financial Economics, 31(1), pp.43-73.

Houthakker, H.S., 1961. Systematic and random elements in short-term price movements. The American Economic Review, 51(2), pp.164-172. 
Jegadeesh, N. and Titman, S., 1993. Returns to buying winners and selling losers: Implications for stock market efficiency. The Journal of Finance, 48(1), pp.65-91.

Keynes, J.M., 1930. A treatise on money: in 2 volumes. Macmillan \& Company.

Kim, A.Y., Tse, Y., and Wald, J.K., 2016, Time series momentum and volatility scaling. Journal of Financial Markets 30, 103-124.

Koijen, R.S.J., Moskowitz, T.J., Pedersen, L. H., and Vrugt, E.B., 2018, Carry. Journal of Financial Economics 127, 197-225.

LeRoy, S.F., 1973. Risk aversion and the martingale property of stock prices. International Economic Review, pp.436-446.

Lucas Jr, R.E., 1978. Asset prices in an exchange economy. Econometrica: Journal of the Econometric Society, pp.1429-1445.

McFarren, T., 2013. VIX your portfolio: Selling volatility to improve performance. Blackrock Investment Insights, Vol 16, Issue 2, 1-21.

Mencia, J. and Sentana, E., 2013. Valuation of VIX derivatives. Journal of Financial Economics, 108(2), pp.367-391.

Mixon, S. and Onur, E., 2014. Volatility derivatives in practice: activity and impact. Unpublished Working Paper, Commodity Futures and Trading Commission.

Moskowitz, T.J., Ooi, Y.H. and Pedersen, L.H., 2012. Time series momentum. Journal of Financial Economics, 104(2), pp.228-250.

Muth, J.F., 1961. Rational expectations and the theory of price movements. Econometrica 29, pp 315-335.

Nagel, S., 2012, Evaporating liquidity, Review of Financial Studies 25, pp. 2005-2039.

Newey, W.K., and West, K.D., 1987. A simple, positive semi-definite, heterosketasticity and autocorrelation consistent covariance matrix. Econometrica 55, pp. 703-708.

Prescott, E and Mehra, R. Recursive competitive equilibrium: The case of homogenous households. Econometrica 48, pp 1365-1379.

Samuelson, P.A., 1965. Proof that properly anticipated prices fluctuate randomly. IMR; Industrial Management Review (pre-1986), 6(2), p.41. 
Sheikh, A.M., 1993. The behavior of volatility expectations and their effects on expected returns. Journal of Business, pp.93-116.

Szado, E., 2009. VIX Futures and options: A Case Study of Portfolio Diversification During the 2008 Financial Crisis. The Journal of Alternative Investments, 12(2), pp.68-85.

Todorov, V., 2009. Variance risk-premium dynamics: The role of jumps. The Review of Financial Studies, 23(1), pp.345-383.

Whaley, R.E., 2013. Trading volatility: At what cost? Journal of Portfolio Management, 40(1), p.95.

Winig, E., Tongberg, K., and Jones, A., 2011. The benefits of selling volatility, Cambridge Associates. 


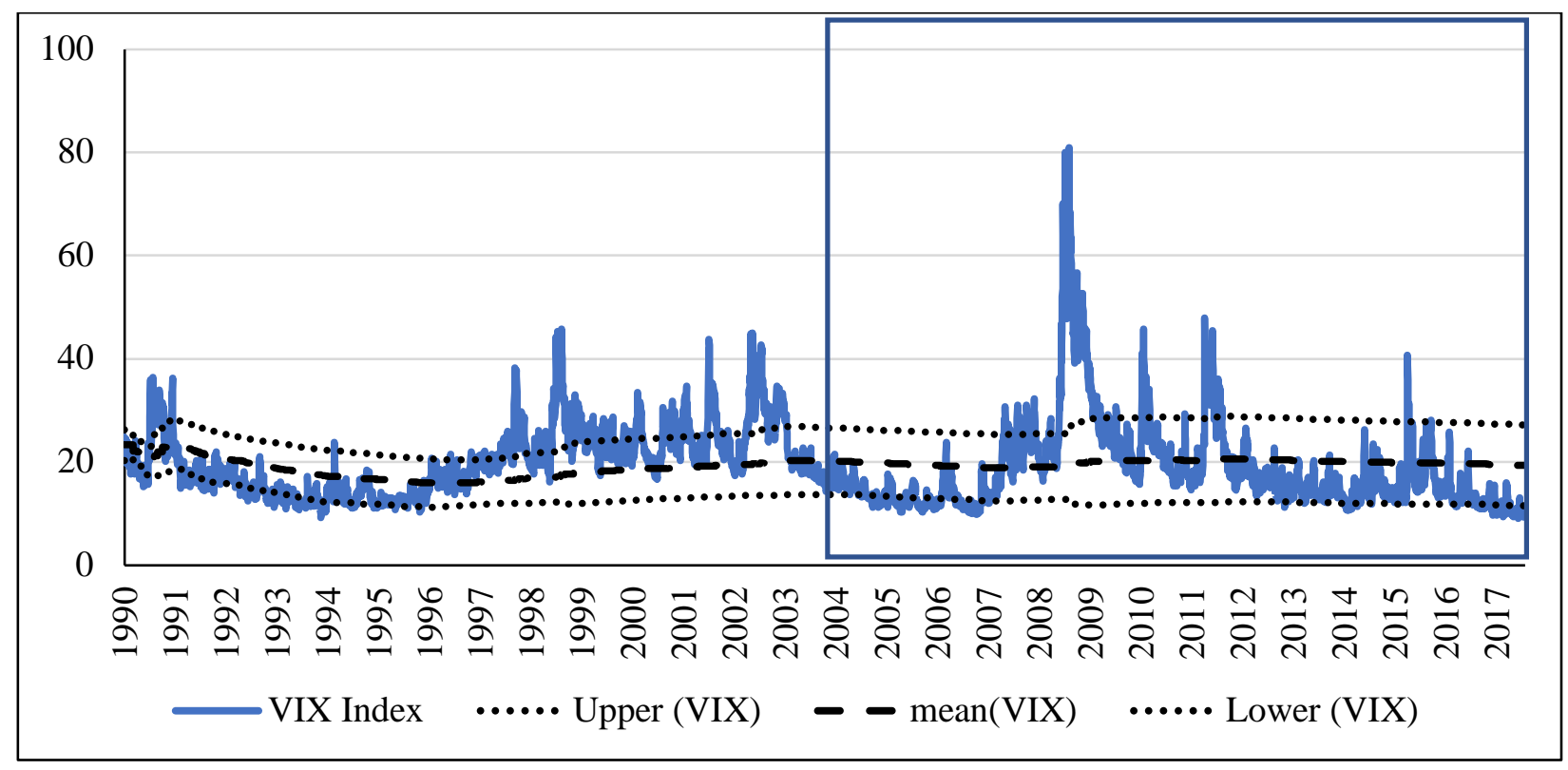

Figure 1. Daily VIX over 1990-2017 (solid line). The plot shows the daily VIX level (solid line), historical mean (dash), and one standard deviation confidence bands (dotted). Historical mean and standard deviations are computed using an expanding window of daily VIX. The rectangle highlights the subperiod during which VIX futures are traded (2004-2017). 

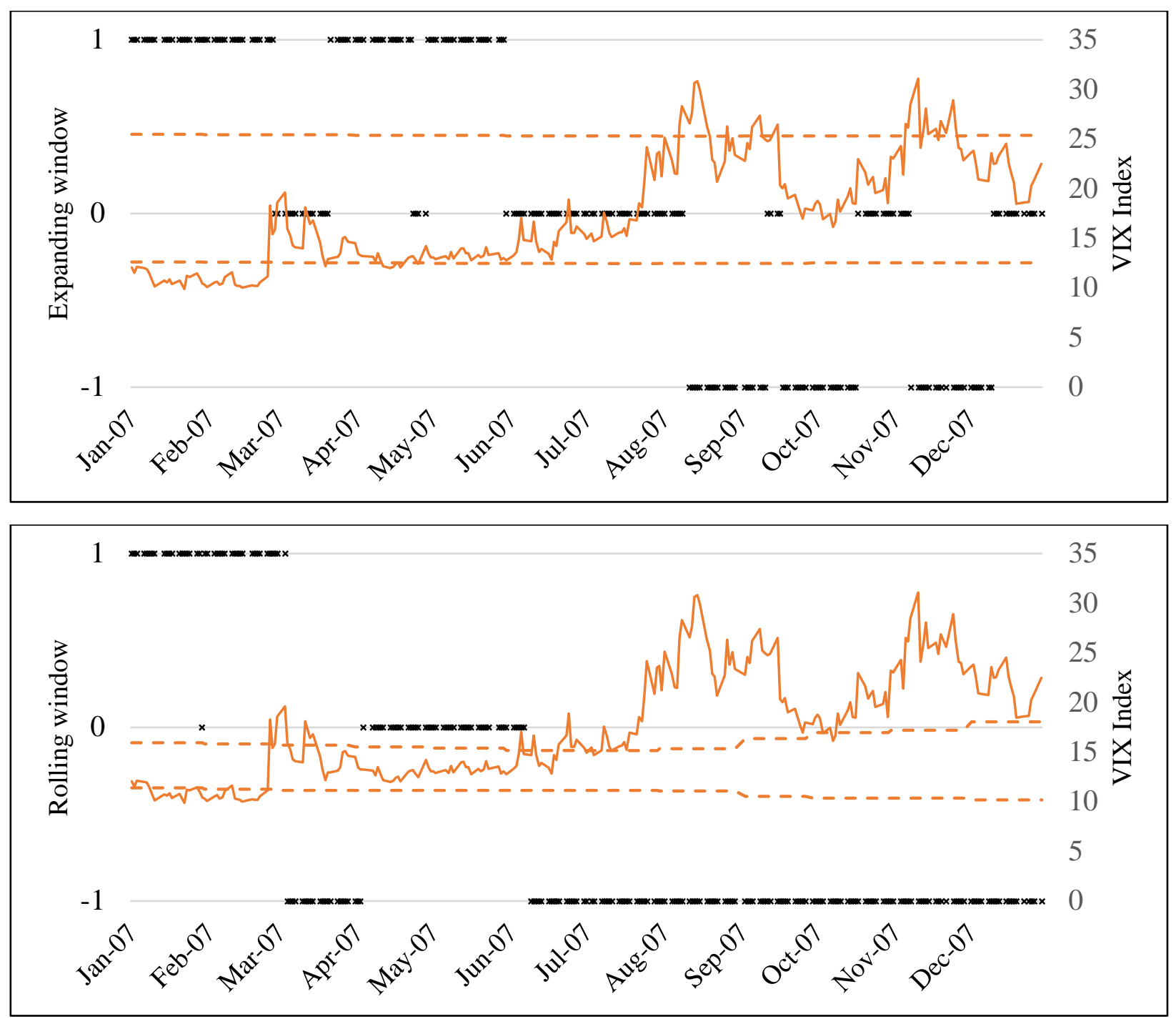

Figure 2. Daily VIX futures positions of level strategies over 2007 (dotted lines). Long, short, and cash positions are represented by dashes at $-1,0$, and +1 , respectively. Top and bottom panels correspond to expanding and 36-month rolling windows to compute VIX confidence bands, respectively. Both panels also show the level (solid line) and one-standard deviation confidence bands (dashed line) of VIX. 

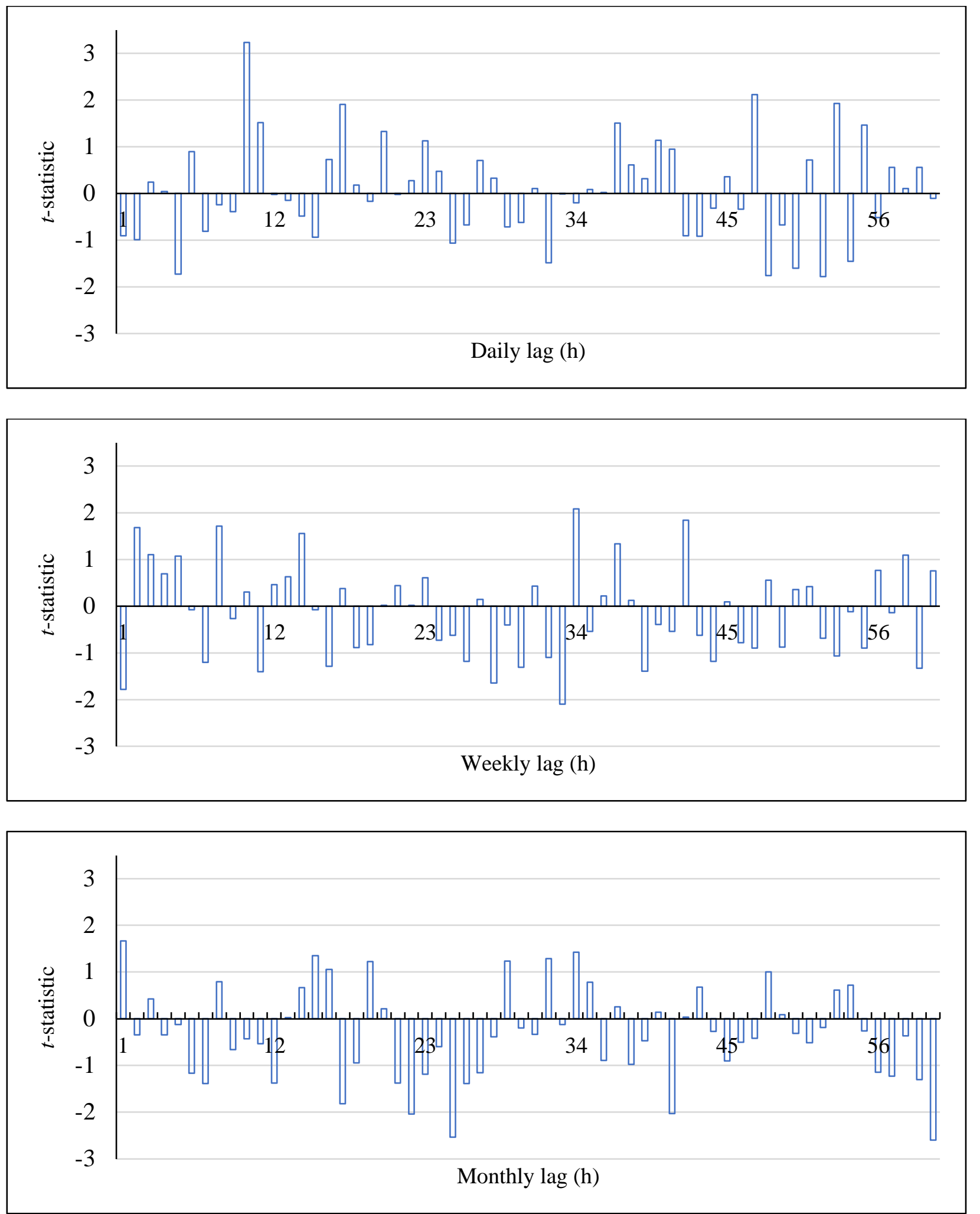

Figure 3. Time series predictability of VIX futures returns. We regress the daily, weekly, and monthly return of near-term VIX futures contracts on the lagged level of VIX and the lagged futures and over various horizons (h): $R_{F(V I X), t}=\alpha+\beta_{h} R_{F(V I X), t-h}+\delta V I X_{t-1}+\varepsilon_{t}$. The figure shows t-statistics for the coefficient on $\mathrm{R}_{\mathrm{F}(\mathrm{VIX}), \mathrm{t}-\mathrm{h}}$ computed using robust standard errors. 


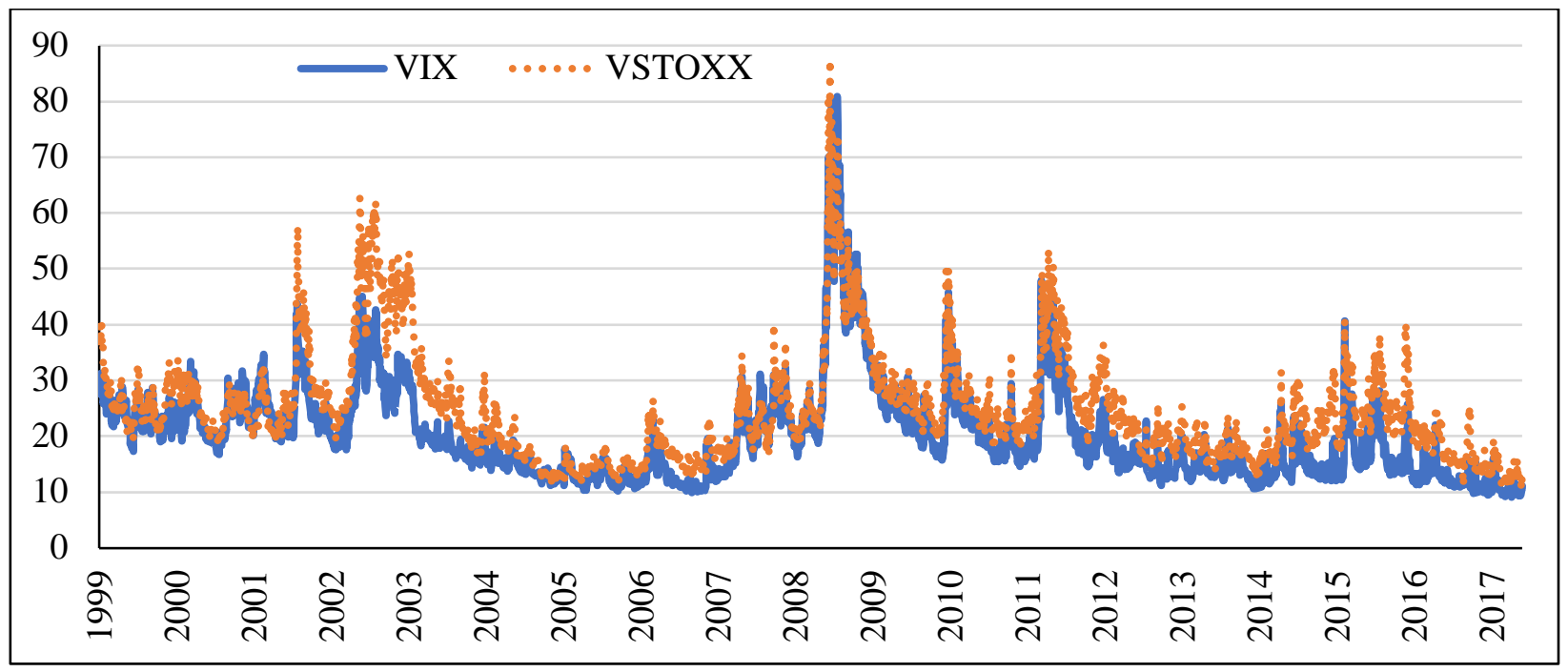

Figure 4. Volatility indices over 1999-2017. The daily levels of the VSTOXX (dotted line) and VIX (solid line). 


\section{Table 1}

\section{Daily, weekly and monthly returns on the VIX and VIX Futures}

Panel A presents descriptive statistics for the level of the VIX, arithmetic returns on the VIX $\left(\mathrm{R}_{\mathrm{VIX}}\right)$, and continuously compounded returns on the VIX $\left(\ln \left(1+\mathrm{R}_{\mathrm{VIX}}\right)\right)$. The second part of the panel contains similar statistics for arithmetic returns on the VIX futures $\left(R_{F(V I X)}\right)$ and continuously compounded returns on the VIX futures $\left(\ln \left(1+\mathrm{R}_{\mathrm{F}(\mathrm{VIX})}\right)\right)$ at daily, weekly and monthly horizons. Panel B contains Spearman correlations between various monthly returns on the VIX, its futures contract and the CRSP value-weighted market return.

Panel A: Descriptive Statistics

\begin{tabular}{|c|c|c|c|c|c|c|}
\hline & Mean & Std. Dev. & Min & Max & Skewness & $\rho(1)$ \\
\hline \multicolumn{7}{|l|}{ Daily Returns } \\
\hline$V I X$ & 18.57 & 9.07 & 9.14 & 80.86 & 2.60 & 0.98 \\
\hline$R_{V I X}$ & 0.24 & 7.29 & -29.57 & 64.22 & 1.37 & -0.09 \\
\hline $\ln \left(1+R_{V I X}\right)$ & -0.02 & 7.04 & -35.06 & 49.60 & 0.72 & -0.10 \\
\hline$R_{F(V I X)}$ & -0.23 & 4.53 & -25.53 & 35.83 & 1.16 & -0.02 \\
\hline $\ln \left(1+R_{F(V I X)}\right)$ & -0.33 & 4.46 & -29.48 & 30.62 & 0.70 & -0.03 \\
\hline \multicolumn{7}{|c|}{ Weekly Returns } \\
\hline$R_{V I X}$ & 0.76 & 13.64 & -35.73 & 98.82 & 1.60 & -0.20 \\
\hline $\ln \left(1+R_{V I X}\right)$ & -0.09 & 12.82 & -44.20 & 68.72 & 0.56 & -0.22 \\
\hline$R_{F(V I X)}$ & -1.17 & 9.72 & -28.56 & 63.64 & 1.67 & -0.07 \\
\hline $\ln \left(1+R_{F(V I X)}\right)$ & -1.62 & 9.33 & -33.64 & 49.25 & 0.91 & -0.09 \\
\hline \multicolumn{7}{|c|}{ Monthly Returns } \\
\hline$R_{V I X}$ & 1.96 & 22.47 & -38.49 & 134.57 & 1.87 & -0.17 \\
\hline $\ln \left(1+R_{V I X}\right)$ & -0.17 & 20.09 & -48.60 & 85.26 & 0.64 & -0.23 \\
\hline$R_{F(V I X)}$ & -4.90 & 20.67 & -37.80 & 106.67 & 2.02 & 0.16 \\
\hline $\ln \left(1+R_{F(V I X)}\right)$ & -7.01 & 19.33 & -47.48 & 72.59 & 0.96 & 0.08 \\
\hline \multicolumn{7}{|c|}{ Panel B: Spearman Correlations } \\
\hline & $\mathrm{R}_{\mathrm{F}(\mathrm{VIX})}$ & $\ln \left(1+\mathrm{R}_{\mathrm{F}(\mathrm{VIX})}\right)$ & $\mathrm{R}_{\mathrm{VIX}}$ & $\ln \left(1+\mathrm{R}_{\mathrm{VIX}}\right)$ & $\mathrm{R}_{\mathrm{MKT}}$ & $\ln \left(1+\mathrm{R}_{\mathrm{MKT}}\right)$ \\
\hline$R_{F(V I X)}$ & 1.00 & & & & & \\
\hline $\ln \left(1+R_{F(V I X)}\right)$ & 0.98 & 1.00 & & & & \\
\hline$R_{V I X}$ & 0.81 & 0.82 & 1.00 & & & \\
\hline $\ln \left(1+R_{V I X}\right)$ & 0.80 & 0.83 & 0.98 & 1.00 & & \\
\hline$R_{M K T}$ & -0.77 & -0.77 & -0.67 & -0.69 & 1.00 & \\
\hline $\ln \left(1+R_{M K T}\right)$ & -0.77 & -0.78 & -0.67 & -0.69 & 1.00 & 1.00 \\
\hline
\end{tabular}




\section{Predicting VIX Futures Returns}

Table 2

The table presents coefficients from time series regressions of daily, weekly and monthly VIX futures returns on prior levels of the VIX. The regressions use arithmetic $\left(\mathrm{R}_{\mathrm{F}(\mathrm{VIX})}\right)$ or continuously compounded returns $\left(\ln \left(1+\mathrm{R}_{\mathrm{F}(\mathrm{VIX})}\right)\right)$. $\mathrm{VIX}_{\mathrm{t}-1}$ is the level of the VIX in the prior day, week or month. We use extended or rolling averages to demean the VIX. VIX $X_{t-1}-\overline{V I X}_{e, t-1}$ is the prior level of the VIX minus the time series average VIX from 1990 to t-1. VIX $X_{t-1^{-}}$ $V I X_{r, t-1}$ is the prior level of the VIX minus the time series average VIX from the prior 36 months. T-statistics appear in parentheses.

$\mathrm{R}_{\mathrm{F}(\mathrm{VIX})}$

Panel A: Daily Regressions

\begin{tabular}{|c|c|c|c|c|c|c|}
\hline Intercept & $\begin{array}{r}-0.0029 \\
(1.42)\end{array}$ & $\begin{array}{r}-0.0023 \\
(2.78)\end{array}$ & $\begin{array}{r}-0.0022 \\
(2.74)\end{array}$ & $\begin{array}{r}-0.0030 \\
(1.49)\end{array}$ & $\begin{array}{r}-0.0033 \\
(4.15)\end{array}$ & $\begin{array}{r}-0.0033 \\
(4.12)\end{array}$ \\
\hline$V I X_{t-1}$ & $\begin{array}{r}0.0031 \\
(0.26)\end{array}$ & - & - & $\begin{array}{r}-0.0018 \\
(0.15)\end{array}$ & - & - \\
\hline$V I X_{t-1}-\overline{V I X}_{e, t-1}$ & - & $\begin{array}{r}0.0040 \\
(0.34)\end{array}$ & - & - & $\begin{array}{r}-0.0008 \\
(0.07)\end{array}$ & - \\
\hline$V I X_{t-1}-\overline{V I X}_{r, t-1}$ & - & - & $\begin{array}{r}0.0098 \\
(0.82)\end{array}$ & & & $\begin{array}{r}0.0049 \\
(0.41)\end{array}$ \\
\hline$A d j-R^{2}$ & 0.000 & 0.000 & $\begin{array}{r}(0.02) \\
0.000\end{array}$ & 0.000 & 0.000 & 0.000 \\
\hline \multicolumn{7}{|c|}{ Panel B: Weekly Regressions } \\
\hline Intercept & $\begin{array}{r}-0.0162 \\
(1.85)\end{array}$ & $\begin{array}{r}-0.0113 \\
(3.02)\end{array}$ & $\begin{array}{r}-0.0110 \\
(3.00)\end{array}$ & $\begin{array}{r}-0.0176 \\
(2.11)\end{array}$ & $\begin{array}{r}-0.0160 \\
(4.51)\end{array}$ & $\begin{array}{r}-0.0158 \\
(4.50)\end{array}$ \\
\hline$V I X_{t-1}$ & $\begin{array}{r}0.0248 \\
(0.51)\end{array}$ & - & - & $\begin{array}{r}0.0074 \\
(0.16)\end{array}$ & - & - \\
\hline$V I X_{t-1}-\overline{V I X}_{e, t-1}$ & - & $\begin{array}{r}0.0293 \\
(0.59)\end{array}$ & - & - & $\begin{array}{r}0.0120 \\
(0.26)\end{array}$ & - \\
\hline$V I X_{t-1^{-}}-V I X_{r, t-1}$ & - & - & $\begin{array}{r}0.0575 \\
(1.14)\end{array}$ & - & - & $\begin{array}{r}0.0398 \\
(0.84)\end{array}$ \\
\hline$A d j-R^{2}$ & 0.001 & 0.001 & 0.003 & 0.000 & 0.000 & 0.001 \\
\hline \multicolumn{7}{|c|}{ Panel C: Monthly Regressions } \\
\hline Intercept & $\begin{array}{r}-0.0694 \\
(1.57)\end{array}$ & $\begin{array}{r}-0.0474 \\
(2.47)\end{array}$ & $\begin{array}{r}-0.0462 \\
(2.51)\end{array}$ & $\begin{array}{r}-0.0714 \\
(1.83)\end{array}$ & $\begin{array}{r}-0.0697 \\
(4.07)\end{array}$ & $\begin{array}{r}-0.0683 \\
(4.16)\end{array}$ \\
\hline$V I X_{t-1}$ & $\begin{array}{r}0.1094 \\
(0.40)\end{array}$ & - & - & $\begin{array}{r}0.0069 \\
(0.03)\end{array}$ & - & - \\
\hline$V I X_{t-1}-\overline{V I X}_{e, t-1}$ & - & $\begin{array}{r}0.1318 \\
(0.47)\end{array}$ & - & - & $\begin{array}{r}0.0299 \\
(0.13)\end{array}$ & - \\
\hline$V I X_{t-1}-\overline{V I X}_{r, t-1}$ & - & - & $\begin{array}{r}0.2631 \\
(0.91)\end{array}$ & - & - & $\begin{array}{r}0.1742 \\
(0.73)\end{array}$ \\
\hline$A d j-R^{2}$ & 0.002 & 0.003 & 0.011 & 0.000 & 0.000 & 0.006 \\
\hline
\end{tabular}


Table 3

\section{Daily Profits of mean reversion strategies}

In Panel A, the strategy goes long (short) VIX futures when the VIX falls one standard deviation below (above) its historical average (expanding window). If the VIX is within one standard deviation of the mean, the strategy stays in cash. The holding period for long/short positions is 22 days but the means and standard deviations are updated daily. The strategy in Panel B is identical except that the means and standard deviations are calculated over the prior 36 months (rolling window). In Panels C and D, this strategy is overlaid with a momentum filter so that long (short) positions are only taken if the return on the VIX futures is positive (negative) over the past month.

$$
\begin{gathered}
\text { Volatility risk } \\
\text { premium } \\
\text { adjusted } \\
\text { returns }
\end{gathered}
$$$$
\text { Unadjusted }
$$$$
\text { returns }
$$

Number of Days

Panel A: Expanding window

All

Short leg only

Cash leg only

\begin{tabular}{|c|c|c|c|c|c|c|c|}
\hline All & 3441 & -0.08 & -1.19 & 0.01 & 0.08 & -0.02 & -0.38 \\
\hline Short leg only & 814 & 0.05 & 0.23 & -0.19 & -0.92 & -0.22 & -1.10 \\
\hline Cash leg only & 1184 & 0.00 & & 0.00 & & 0.00 & \\
\hline Long leg only & 1443 & -0.21 & -2.02 & 0.12 & 1.13 & 0.07 & 0.65 \\
\hline \multicolumn{8}{|c|}{ Panel C: Expanding window with momentum filter } \\
\hline All & 3441 & 0.04 & 1.56 & 0.04 & 1.49 & 0.03 & 1.31 \\
\hline Short leg only & 308 & 0.46 & 1.69 & 0.29 & 1.07 & 0.27 & 0.97 \\
\hline Cash leg only & 3023 & 0.00 & & 0.00 & & 0.00 & \\
\hline Long leg only & 110 & -0.03 & -0.09 & 0.39 & 1.42 & 0.32 & 1.19 \\
\hline \multicolumn{8}{|c|}{ Panel D: Rolling 36 month window with momentum filter } \\
\hline All & 3441 & -0.02 & -0.72 & -0.04 & -1.17 & -0.04 & -1.35 \\
\hline Short leg only & 396 & -0.12 & -0.48 & -0.35 & -1.39 & -0.39 & -1.52 \\
\hline Cash leg only & 2913 & 0.00 & & 0.00 & & 0.00 & \\
\hline Long leg only & 132 & -0.23 & -0.73 & 0.09 & 0.31 & 0.06 & 0.15 \\
\hline
\end{tabular}

Long leg only

Panel B: Rolling 36 month window
Volatility risk premium adjusted net returns mean $\quad t$-stat

mean $t$-stat

$\begin{array}{lll}0.01 & 0.19 & -0.01\end{array}$

$-0.08$

$-0.24$

$-0.05 \quad-0.22$

$-0.36$

0.00

0.00

$0.06 \quad 0.57$

0.01

0.07

1031

0.00

$-2.61$ 


\section{Table 4}

\section{Monthly returns to time series momentum strategies using VIX futures}

Momentum portfolios are formed each month using the lookback and holding periods shown below (in months). For lookback and holding periods longer than one month, this generates overlapping portfolios. The return for month $\mathrm{t}$ is the equal weighted average of all overlapping portfolios in that month. The second column shows the number of portfolios in which the strategy is short VIX futures. Panel A shows average monthly returns to such portfolios. Panel B subtracts (adds) the historical average passive return to VIX futures from the long (short) leg of the strategy to compute benchmark adjusted returns. Panel $\mathrm{C}$ uses returns constructed from purchase and sale decisions at the prevailing ask and bid price respectively. T-statistics in parentheses.

\begin{tabular}{|c|c|c|c|c|c|c|}
\hline \multirow{2}{*}{$\begin{array}{l}\text { Lookback Period } \\
\text { (Months) }\end{array}$} & \multirow[b]{2}{*}{$\%$ Months Short } & \multicolumn{5}{|c|}{ Holding Period (Months) } \\
\hline & & 1 & 3 & 6 & 9 & 12 \\
\hline \multicolumn{7}{|c|}{ Panel A: Unadjusted Returns } \\
\hline \multirow[t]{2}{*}{1} & 66.24 & 3.33 & 2.13 & 1.58 & 1.69 & 1.33 \\
\hline & & $(1.92)$ & $(2.15)$ & $(2.00)$ & $(2.28)$ & $(1.87)$ \\
\hline \multirow[t]{2}{*}{3} & 72.72 & 4.43 & 2.18 & 1.40 & 1.51 & 1.86 \\
\hline & & $(2.59)$ & $(1.79)$ & $(1.33)$ & $(1.61)$ & $(2.09)$ \\
\hline \multirow[t]{2}{*}{6} & 76.62 & 3.13 & 1.81 & 1.99 & 2.03 & 2.39 \\
\hline & & $(1.81)$ & $(1.26)$ & $(1.58)$ & $(1.77)$ & $(2.17)$ \\
\hline \multirow[t]{2}{*}{9} & 75.97 & 1.81 & 1.20 & 1.60 & 1.83 & 2.16 \\
\hline & & $(1.04)$ & $(0.8)$ & $(1.23)$ & $(1.51)$ & $(1.86)$ \\
\hline \multirow[t]{2}{*}{12} & 73.97 & 1.19 & 0.50 & 1.14 & 1.42 & 1.24 \\
\hline & & $(0.68)$ & $(0.34)$ & $(0.80)$ & $(1.03)$ & $(0.96)$ \\
\hline \multicolumn{7}{|c|}{ Panel B: Volatility risk premium adjusted returns } \\
\hline \multirow[t]{2}{*}{1} & & 1.52 & 0.29 & -0.30 & -0.18 & -0.51 \\
\hline & & $(0.88)$ & $(0.31)$ & $(0.39)$ & $(0.24)$ & $(0.70)$ \\
\hline \multirow[t]{2}{*}{3} & & 1.89 & -0.39 & -1.16 & -1.03 & -0.68 \\
\hline & & $(1.10)$ & $(0.32)$ & $(1.10)$ & $(1.09)$ & $(0.75)$ \\
\hline \multirow[t]{2}{*}{6} & & 0.05 & -1.28 & -1.09 & -1.06 & -0.71 \\
\hline & & $(0.03)$ & $(0.89)$ & $(0.87)$ & $(0.93)$ & $(0.64)$ \\
\hline \multirow[t]{2}{*}{9} & & -1.34 & -1.95 & -1.53 & -1.31 & -0.98 \\
\hline & & $(0.77)$ & $(1.34)$ & $(1.21)$ & $(1.10)$ & $(0.85)$ \\
\hline \multirow[t]{2}{*}{12} & & -1.89 & -2.57 & -1.91 & -1.64 & -1.79 \\
\hline & & $(1.10)$ & $(1.81)$ & $(1.38)$ & $(1.20)$ & $(1.39)$ \\
\hline \multicolumn{7}{|c|}{ Panel C: Volatility risk premium adjusted net returns } \\
\hline \multirow[t]{2}{*}{1} & & 0.36 & -0.48 & -0.77 & -0.71 & -0.93 \\
\hline & & $(0.20)$ & $(0.43)$ & $(0.91)$ & $(0.85)$ & (1.18) \\
\hline \multirow[t]{2}{*}{3} & & 0.98 & -0.88 & -1.62 & -1.49 & -1.14 \\
\hline & & $(0.55)$ & $(0.69)$ & $(1.55)$ & $(1.5)$ & (1.19) \\
\hline \multirow[t]{2}{*}{6} & & -0.81 & -1.65 & -1.53 & -1.52 & -1.19 \\
\hline & & $(0.46)$ & (1.18) & $(1.23)$ & $(1.29)$ & (1.03) \\
\hline \multirow[t]{2}{*}{9} & & -2.22 & -2.31 & -1.97 & -1.83 & -1.53 \\
\hline & & $(1.27)$ & (1.61) & $(1.51)$ & $(1.44)$ & $(1.24)$ \\
\hline \multirow[t]{2}{*}{12} & & -2.67 & -2.96 & -2.48 & -2.22 & -2.33 \\
\hline & & $(1.55)$ & $(2.09)$ & $(1.74)$ & $(1.60)$ & $(1.77)$ \\
\hline
\end{tabular}




\section{Predicting VSTOXX Futures Returns}

Table 5

The table presents time series regressions of daily, weekly and monthly VSTOXX futures returns on prior levels of the VSTOXX index. The regressions use arithmetic $\left(\mathrm{R}_{\mathrm{F}(\mathrm{VSTOXX})}\right)$ or continuously compounded returns $\left(\ln \left(1+\mathrm{R}_{\mathrm{F}(\mathrm{VSTOXX})}\right)\right)$. VSTOXX $\mathrm{V}_{\mathrm{t}-1}$ is the level of VSTOXX in the prior day, week or month. We use extended or rolling averages to demean VSTOXX. $\operatorname{VSTOXX} X_{t-1}-\overline{V S T O X X}_{e, t-1}$ is the prior level of VSTOXX minus the time series average VSTOXX from 2004 to t-1. VSTOXX $\overline{t-1}^{-} \overline{\operatorname{VSTOXX}}_{r, t-1}$ is the prior level of VSTOXX minus the time series average VSTOXX from the prior XX days, weeks or months. T-statistics appear in parentheses.

Panel A: Daily Regressions

Intercept

$\operatorname{VSTOXX} X_{t-1}$

$\operatorname{VSTOXX} X_{t-1}-\overline{\operatorname{VSTOXX}}_{e, t-1}$

$\operatorname{VSTOXX} X_{t-1}-\overline{\operatorname{VSTOXX}}_{r, t-1}$

$A d j-R 2$

Panel B: Weekly Regressions

Intercept

$\operatorname{VSTOXX} X_{t-1}$

$\operatorname{VSTOXX} X_{t-1}-\overline{\operatorname{VSTOXX}}_{e, t-1}$

$\operatorname{VSTOXX} X_{t-1}-\overline{\operatorname{VSTOXX}}_{r, t-1}$

$A d j-R 2$

Panel C: Monthly Regressions

Intercept

$\operatorname{VSTOXX} X_{t-1}$

$\operatorname{VSTOXX} X_{t-1}-\overline{\operatorname{VSTOXX}}_{e, t-1}$

$\operatorname{VSTOXX} X_{t-1}-\overline{\operatorname{VSTOXX}}_{r, t-1}$

\section{$\mathrm{R}_{\mathrm{F} \text { (VSTOXX) }}$}

$(0.57)$

$-0.0739$

(1.26)

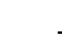

$-0.0754$

(1.24)

0.003

0.003

$(0.81)$

(2.28)

$-0.4044$

(1.41)

- -0.4166

(1.44)

$\begin{array}{rrrrrr}0.0005 & -0.0022 & -0.0021 & 0.0008 & -0.0032 & -0.0030 \\ (0.15) & (1.88) & (1.81) & (0.23) & (2.77) & (2.71) \\ -0.0105 & - & - & -0.0154 & - & - \\ (0.66) & & & (0.98) & & \\ - & -0.0104 & - & - & -0.0156 & - \\ & (0.64) & & & (0.96) & \\ - & - & -0.0070 & - & - & -0.0125 \\ & & (0.41) & & & (0.74) \\ 0.000 & 0.000 & 0.000 & 0.001 & 0.001 & 0.000\end{array}$

$\begin{array}{lll}0.000 & 0.000 & 0.000\end{array}$

$\begin{array}{lll}0.0075 & -0.0115 & -0.0110\end{array}$

(2.33) (2.22)

$\begin{array}{lll}- & - & -0.0634\end{array}$

$(0.93)$

0.002

$\begin{array}{lll}0.0542 & -0.0501 & -0.0475\end{array}$

$(2.25)$

$$
\text { - } \quad-\quad-0.3586
$$

(1.52)

$\begin{array}{lll}0.017 & 0.017 & 0.011\end{array}$

$\ln \left(1+\mathrm{R}_{\mathrm{F}(\text { Vstoxx })}\right)$

0.001

$\begin{array}{rrr}0.0084 & -0.0164 & -0.0159 \\ (0.63) & (3.39) & (3.26) \\ -0.0963 & - & -\end{array}$

(1.62)

- $\quad-0.0991$

(1.61)

- $\quad-\quad-0.0878$

$\begin{array}{lll}0.005 & 0.005 & 0.004\end{array}$

$\begin{array}{lll}0.0543 & -0.0711 & -0.0683\end{array}$

$\begin{array}{lll}(0.83) & (3.38) \quad(3.33)\end{array}$

$-0.4860$

(1.73)

- -0.5035

(1.77)

- $\quad$ - -0.4470

(1.84) 


\section{Table 6}

\section{Monthly returns to time series momentum strategies using VSTOXX futures}

Momentum portfolios are formed each month using the lookback and holding periods shown below (in months). For lookback and holding periods longer than one month, this generates overlapping portfolios. The return for month $t$ is the equal weighted average of all overlapping portfolios in that month. The second column shows the number of portfolios in which the strategy is short VSTOXX futures. Panel A shows average monthly returns to such portfolios. Panel B subtracts (adds) the historical average passive return to VSTOXX futures from the long (short) leg of the strategy to compute benchmark adjusted returns. Panel $\mathrm{C}$ adjusts these returns with returns constructed from purchase and sale decisions at the ask and bid price respectively. T-statistics in parentheses.

Holding Period (Months)

Lookback Period \% Months Short

$1+3 \quad 6$

Panel A: Unadjusted Returns

$\begin{array}{rrrrrrr}1 & 64.80 & -0.36 & 1.75 & 1.95 & 2.28 & 2.03 \\ & & (0.17) & (1.53) & (2.22) & (2.73) & (2.50) \\ 3 & 68.08 & 4.60 & 3.25 & 2.62 & 2.87 & 2.41 \\ & & (2.26) & (2.04) & (2.19) & (2.55) & (2.16) \\ 6 & 70.21 & 5.42 & 3.87 & 3.29 & 2.75 & 1.67 \\ & & (2.70) & (2.29) & (2.04) & (1.75) & (1.14) \\ 9 & 68.03 & 4.72 & 3.57 & 2.78 & 1.88 & 0.90 \\ & & (2.32) & (1.82) & (1.44) & (1.05) & (0.55) \\ 12 & 64.73 & 3.49 & 2.48 & 1.72 & 1.11 & 0.22 \\ & & (1.70) & (1.25) & (0.88) & (0.62) & (0.14)\end{array}$

Panel B: Volatility risk premium adjusted returns

\begin{tabular}{|c|c|c|c|c|c|}
\hline \multirow[t]{2}{*}{1} & -1.72 & 0.47 & 0.71 & 0.82 & 0.60 \\
\hline & $(0.83)$ & $(0.41)$ & $(0.82)$ & (1.03) & $(0.76)$ \\
\hline \multirow[t]{2}{*}{3} & 2.77 & 1.41 & 0.82 & 1.10 & 0.65 \\
\hline & $(1.35)$ & $(0.87)$ & $(0.69)$ & $(0.97)$ & $(0.58)$ \\
\hline \multirow[t]{2}{*}{6} & 3.15 & 1.56 & 0.99 & 0.46 & -0.56 \\
\hline & $(1.54)$ & $(0.93)$ & $(0.62)$ & $(0.29)$ & $(0.38)$ \\
\hline \multirow[t]{2}{*}{9} & 2.49 & 1.32 & 0.54 & -0.33 & -1.22 \\
\hline & $(1.21)$ & $(0.67)$ & $(0.28)$ & $(0.18)$ & $(0.74)$ \\
\hline \multirow[t]{2}{*}{12} & 1.46 & 0.46 & -0.27 & -0.82 & -1.61 \\
\hline & $(0.71)$ & $(0.23)$ & $(0.14)$ & $(0.45)$ & $(0.98)$ \\
\hline \multicolumn{6}{|c|}{ Panel C: Volatility risk premium adjusted net returns } \\
\hline \multirow[t]{2}{*}{1} & -3.64 & -0.44 & -0.07 & 0.09 & -0.07 \\
\hline & $(1.74)$ & $(0.34)$ & $(0.07)$ & $(0.10)$ & $(0.07)$ \\
\hline \multirow[t]{2}{*}{3} & 0.53 & 0.28 & -0.21 & 0.13 & -0.29 \\
\hline & $(0.25)$ & $(0.17)$ & $(0.16)$ & $(0.11)$ & $(0.24)$ \\
\hline \multirow[t]{2}{*}{6} & 0.55 & 0.27 & -0.12 & -0.81 & -1.58 \\
\hline & $(0.26)$ & $(0.16)$ & $(0.08)$ & $(0.52)$ & $(1.06)$ \\
\hline \multirow[t]{2}{*}{9} & -0.30 & 0.05 & -1.04 & -1.77 & -2.67 \\
\hline & $(0.14)$ & $(0.02)$ & $(0.56)$ & (1) & $(1.66)$ \\
\hline \multirow[t]{2}{*}{12} & -1.30 & -1.36 & -2.23 & -2.86 & -3.46 \\
\hline & $(0.61)$ & $(0.69)$ & (1.18) & $(1.60)$ & $(2.08)$ \\
\hline
\end{tabular}

Panel C: Volatility risk premium adjusted net returns 


\section{Appendix}

Koijen et al. (2018) show that Carry, defined as the return to the futures position when the spot price stays constant, predicts futures returns across a variety of assets. They speculate that this might also be the case for VIX futures (footnote 11) but do not explicitly study the possibility. Bessembinder (2018) uses a related variable, the Roll Yield, defined as the difference between the futures return and the change in the spot price. He too suggests that the slope should predict VIX futures returns. He points out that VIX futures returns should be approximately equal to the sum of roll yields over intervals that begin and end with volatility near its stationary mean. In other words, the negative risk premium in VIX Futures (Eraker and Wu (2017), Mencia and Santana (2013)) equals accumulated (negative) roll yields. While slope implied predictability is

not central to our thesis, we estimate regressions similar to those in Table 2 while including Carry. The results are below, in Table A1. As expected, the term structure generates some predictability, consistent with a time varying risk premium. More importantly for our purpose, the lack of predictability from the level of the VIX remain unchanged. 


\section{Table A1}

Predicting VIX Futures Returns with Carry

The table presents coefficients from time series regressions of daily, weekly and monthly VIX futures returns on prior levels of the VIX. VIX $\mathrm{t}_{\mathrm{t}-1}$ is the level of the VIX in the prior day, week or month. VIX ${ }_{1}{ }^{-} \overline{V I X}_{e, t-1}$ is the prior level of the VIX minus the time series average VIX from 1990 to t-1. VIX $X_{t-1^{-}}$ $\overline{V I X}_{r, t-1}$ is the prior level of the VIX minus the time series average VIX from the prior 36 months. Carry is the VIX minus the near term futures price, scaled by the futures price. T-statistics appear in parentheses.

$\mathrm{R}_{\mathrm{F}(\mathrm{VIX})}$

Panel A: Daily Regressions

$V I X_{t-1}$

$V I X_{t-1}-\overline{V I X}_{e, t-1}$

$V I X_{t-1}-\overline{V I X}_{r, t-1}$

Carryt-1

$A d j-R^{2}$
0.0439

$(2.75)$

0.0025
$(0.91)$

$-0.0156$

(1.27)

0.004
$-0.0006$

(0.50)

-

$-0.0150$

(1.20)

$(2.72)$

0.004
$-0.0074$

$(0.59)$

0.0387

(2.46)

-0.0007
$(0.59)$

0.003 $\ln \left(1+\mathrm{R}_{\mathrm{F}(\mathrm{VIX})}\right)$

\begin{tabular}{rrr}
\multicolumn{3}{c}{$\ln \left(1+\mathrm{R}_{\mathrm{F}(\mathrm{VIX})}\right)$} \\
\hline & & \\
& & \\
0.0012 & -0.0019 & -0.0021 \\
$(0.45)$ & $(1.67)$ & $(1.78)$ \\
-0.0158 & - & - \\
$(1.30)$ & & - \\
- & -0.0150 & \\
& $(1.21)$ & - \\
& & -0075 \\
& & $(0.60)$ \\
0.0333 & 0.0329 & 0.0282 \\
$(2.34)$ & $(2.29)$ & $(2.01)$ \\
0.000 & 0.002 & 0.002
\end{tabular}

Panel B: Weekly Regressions

$-0.0122$

0.0333

(0.69)

0.0054

(0.11)

0.0752

(1.20)

0.1008

0.004

0.005
Intercept

0.0045
$(0.38)$
-0.0458

$-0.0046$

$-0.0054$

(0.96)

$V I X_{t-1}$

(0.93)

$V I X_{t-1}-\overline{V I X}_{e, t-1}$

$-0.0414$

$(0.83)$

$V I X_{t-1}-\overline{V I X}_{r, t-1}$

$-0.0020$

(0.04)

0.1558

(2.17)

0.1287

(1.79)

0.009

0.010

-0.03
$(0.32$
-0.038

$(0.81)$

$A d j-R^{2}$

Panel C: Monthly Regressions

Intercept

$V I X_{t-1}$

$V I X_{t-1}-\overline{V I X}_{e, t-1}$

$V I X_{t-1^{-}} \overline{V I X}_{r, t-1}$

Carryt-1

$A d j-R^{2}$
0.9383

$(1.92)$

0.0329

(0.81)

$-0.2464$

(1.59)

0.075
$-0.2292$

$-0.0162$

(0.53)

(0.60)

- $\quad-0.0568$

(0.26)

0.9309

(1.91)

0.074

0.8256

(1.63)

0.067
(1.64)

\begin{tabular}{rrr}
0.0600 & -0.0450 & -0.0474 \\
$(0.16)$ & $(1.79)$ & $(1.88)$ \\
-0.2559 & - & - \\
$(1.50)$ & & \\
- & -0.2350 & - \\
& $(1.36)$ & \\
- & - & -0.0439 \\
& & $(0.21)$ \\
0.6851 & 0.6755 & 0.5599 \\
$(1.89)$ & $(1.86)$ & $(1.47)$ \\
0.045 & 0.044 & 0.036 \\
\hline & &
\end{tabular}

0474

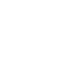

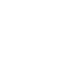

.

